UN IVERSITY OF COPENHAGEN

\title{
Emotional Self-Alienation
}

Szanto, Thomas

Published in:

Midwest Studies in Philosophy

DOI:

10.1111/misp. 12074

Publication date:

2017

Document version

Early version, also known as pre-print

Citation for published version (APA):

Szanto, T. (2017). Emotional Self-Alienation. Midwest Studies in Philosophy, 41(1), 260-286.

https://doi.org/10.1111/misp.12074 
Forthcoming in: Midwest Studies in Philosophy 41 (2017).

PleAse Refer to the PUblished Version.

\title{
Emotional Self-Alienation
}

\author{
Thomas Szanto
}

\begin{abstract}
What is it like to feel alienated from one's own emotions, or emotional self-alienation (ESA)? Drawing on work from critical sociology on emotional capitalism and the commodification of emotions as well as on analytic and phenomenological philosophy of emotions, here, I propose a multi-dimensional account of ESA. I begin by sketching a relational account of alienation, according to which alienation is a deficient relation to oneself, others and the world. Next, I show that ESA is not reducible to cognate but different phenomena such as feelings of being manipulated, coercion or self-deception. I then distinguish between three dimensions of emotions that are deficient in ESA: their experiential, self-disclosing and normative dimension. I argue that ESA involves, first, a certain cleavage between the affective and the intentional dimension of emotions. This results in the loss of personal import of one's emotions and a failure to integrate a given emotion into one's overall evaluative outlook. Secondly, I show that this goes hand in hand with a deficiency in the self-disclosing dimension of emotions. I suggest that in ESA emotions are not revelatory of what matters to oneself. Consequently, ESA hampers an essential function of emotions, namely the elaboration of one's overall personal evaluative outlook. Finally, I argue that ESA also negatively affects the normative dimension of emotions: it disrupts the balance between what I ought to feel and what I actually feel. I conclude by addressing potential misunderstandings of what emotional reappropriation is, and outline how a 'critical theory of emotions' might reply to them.
\end{abstract}

\section{Setting the Stage: Emotional Capitalism and 'Emotion-Invasion'}

Imagine you have worked for the communal unemployment agency for some years. You have professional training as a social worker; your friends consider you the most empathetic person they know. Though you don't see yourself in such a positive light, attending to people in need was indeed always what mattered most to you. Accordingly, solidarity, sympathy and compassion were always built into the heart of your self-image. You not only cognitively and morally appraise these values, but they impact you in a way that the feelings attached to those values 
themselves constitute values for you. Sympathy is not just an abstract value; the very feeling of sympathy matters to you. Now, imagine further that one day a young single mother arrives an hour too late for the scheduled job meeting. She desperately tries to explain the cause of her delay (due to issues at the kindergarten). But you have repeatedly been told by your superior not to make any exceptions to attendance rules, and the monotony of endless interviews has not passed by you without leaving a mark of growing indifference. In the face of the mother's tears you shrug, tell her half-heartedly that you are sorry, and make a note in the respective file, effectuating that she loses a week's allowance payment. However, before going to bed, the mother's tearful face pops up in your mind; you feel uneasiness mounting and eventually overwhelming you. You murmur to yourself: 'Just what have I become?! I don't really feel sympathy any more... But that's not me.'

What happens in this momentary or possibly life-changing crisis? What happens if it's not so much your values or convictions that change but something in the very way they affect you? Suppose you still wholeheartedly hold on to all your previous values and convictions and, contrary to the above scenario, you do make an exception for the mother based on them. What changes, however, is how situations that you were deeply concerned with, cared about, don't really impact you any more. The mother's distress and tears may still bring you to act in certain ways, but they don't move you. In this paper, I shall argue that part of what happens is that you become alienated from your emotions.

The very conceptual interface of 'emotion', 'self and 'alienation', however, might already raise the eyebrows of different philosophical camps. For critical social philosophers, for example, it might seem problematic after decades of poststructuralist, feminist or critical theory inspired critiques of the very concepts of selfhood and alienation (see more, sec. 5). For phenomenologists, the issue might seem superseded by Heidegger's and Sartre's existential-ontological discussion of authenticity. Besides, their specific contribution to affective (in-)authenticity has been sidelined by mainstream analytic and continental philosophers of emotion, even if they have recently attracted some attention (Crowell 2015; Poellner 2015; Withy 2015). It is then no coincidence that, to my knowledge, the last comprehensive treatment of emotions and alienation dates back to 1979, and it is certainly not accidental that it was penned in a Marxist spirit (Heller 1979).

I have two reasons for resurrecting this issue. The first has to do with serious conceptual confusion or underdetermination; for, even if emotional alienation has been treated rather stepmotherly in recent philosophical literature, use of the concept abounds ever since Arlie Hochschild's seminal work on the sociology 
of emotions. ${ }^{1}$ Hochschild introduced the concept side-by-side with the standard concept of alienated labor known from Marx (1844): "beneath the difference between physical and emotional labor", she writes, "there lies a similarity in the possible cost of doing the work: the worker can become estranged or alienated from an aspect of self-either the body or the margins of the soul—that is 'used' to do the work" (Hochschild 1983, 7). Hochschild and subsequent critics of the commodification of emotions have made very productive use of the concept of alienation. Unfortunately, however, within this ever-growing field of research, emotional alienation remains wholly underdetermined. Here is one of the few definitions Hochschild provides:

When elements of [the private emotional system] are taken into the marketplace and sold as human labor, they become stretched into standardized social forms. In these forms, a person's contribution of feeling is thinner, less freighted with consequence; but at the same time it is seen as coming less from the self and being less directed to the other. For that reason it is more susceptible to estrangement. (Hochschild 1983, 13)

But what exactly does it mean that "a person's contribution to feeling" is "thinner", and what is deficient in the relation between emotion and the self (or "the margin of the soul") in emotional alienation? Hochschild and fellow sociologists still owe us clear answers.

The second motivation for this paper stems from a social-critical conviction that many sociologists of emotions share, and above all Hochschild herself: namely that emotional labor and the logics of "emotional capitalism" (Illouz 2007) increasingly make our affective life susceptible to emotional self-alienation.

To be sure, some philosophers of emotion have recently investigated the extent to which external, technological or socio-cultural 'scaffolds' facilitate, enhance or even co-constitute our affective make-up. But these discussions on socalled extended emotions (Krueger 2014; Slaby 2014; Krueger \& Szanto 2017; León et al. forthcoming) often seem, if not in the spirit of emotional capitalism, still too much in line with it. It is high time to supplement their focus and investigate not just emotional extension but also what might be called 'emotional invasion'-a negative modulation of the affective life of individuals by heteronomous, intrusive factors and actors that those individuals cannot identify with or appropriate (cf. Slaby 2017). The present paper is intended as a modest contribution to this task. Its aim lies solely in first clarifying the concept of emotional selfalienation (ESA).

\footnotetext{
${ }^{1}$ A notable philosophical exception is Brewer's essay (2011), and it is telling that Brewer too takes Hochschild as his starting point; see more on his analyis below, sec. 4.

2 Though the term 'emotional self-alienation' should prevent respective misconceptions, it might
} 
In pursuing this aim, I proceed as follows: I begin by outlining a relational account of alienation, according to which alienation is a tripartite deficient relation, or a "relation of relationlessness", to oneself, others and the world (sec. 2). Next, I set the backdrop for clarifying what ESA is by first considering what it is not. In particular, I show that ESA is not reducible to cognate but different phenomena such as feelings of being manipulated, coercion, and self-deception (sec. 3). In the main part (sec. 4), I provide my positive multidimensional account. I distinguish between three dimensions of emotions that are deficient in ESA: the experiential, the self-disclosing and the normative dimensions of emotions. Accordingly, I first argue that ESA involves a blurring of the affective focus of an emotion, or cleavage of the affective and intentional dimensions of emotions. This results in a loss of affective sensitivity and the personal import of one's emotions. Furthermore, I argue that, due to this, one cannot appropriately respond to the value-properties disclosed by one's emotions and ultimately fails to integrate a given emotion into one's overall evaluative outlook. Secondly, I show how this goes hand in hand with a deficiency in the self-disclosing dimension of emotions. Thus, I suggest that in ESA emotions are not revelatory of what matters or what ought to matter to oneself. Consequently, ESA involves a deficient articulation of the self in emotional expression and, more fundamentally, it hampers an essential function of emotions, namely the elaboration of one's personal evaluative outlook, or self-elaboration. Finally, I argue that ESA also negatively affects the normative dimension of emotions: it disrupts the balance between what I ought to feel, according to "feeling rules", and what I actually feel. I explicate this deficiency by drawing on Hochschild's work on emotional labor and management. I demonstrate how the incorporation and habitualization of heteronomous feeling rules leads to an over-regulation of one's emotions, which are in turn experienced as heteronomous. I conclude by addressing potential objections to and misunderstandings of what emotional re-appropriation and authenticity are, and make cursory remarks on how a so-called 'critical theory of emotions' might reply to them (sec. 5).

\section{What is Alienation? Sketch of a Relational Account}

Notwithstanding centuries-long attempts to define the concept, beginning with Hegel, Rousseau and Marx and continuing from Kierkegaard and Heidegger through to generations of Marxist thinkers, sociologists and Critical Theorists (cf. Jaeggi 2005), the philosophical notion of alienation is notoriously vague and not much better determined than its ordinary language counterpart. Indeed its vagueness is due in large part to the fact that it has typically been employed diagnosti- 
cally or normatively rather than descriptively, geared toward socio-political or sociocultural criticism. Its broader semantic field encompasses such phenomena as reification, inauthenticity, role-playing, lack of appropriation or identification, lack of self-mastery, or feelings of being dominated by some Other (the 'alien' in alienation or the 'stranger' in estrangement), be it a person, thing, some system or 'the world'. Regarding an even wider conceptual horizon, we might list cognates such as lack of belonging, conventionalization, a sense of absurdity or loss of existential meaning.

Though the notion of alienation is certainly not synonymous with or reducible to either of these notions, they have a common denominator. As Jaeggi convincingly argues in her masterly comprehensive study, alienation is an essentially relational phenomenon. More precisely, alienation is a "deficient relation", paradoxically formulated as a "relation of relationlessness" (Jaeggi 2005, 25). The deficiency at play in of relationlessness is not "a mere absence" of a relation but points to an ontologically, existentially or historically prior relation that one has had. Moreover, employing the notion of alienation to characterize the deficient quality of a (prior) relation is not just a descriptive enterprise, but also a normative one. It marks the fact that one ought to have the relation that one had or could have had, but doesn't 'own' (any longer) (ibid.). This point is worth emphasizing. After all, relations to other people, things or events that one never ('really') has borne, or owned, in any robust sense of the term 'relation' are infinite. The absence of these relations simply does not matter to the subject. It is of no existential or affective concern whether one has or has owned them. But then indifference rather than alienation characterizes the proper attitude towards them.

Thus, the subject of (self-)alienation always has a relation of personal concern or impact to alienated entities or situations. Moreover, (self-)alienation always involves one's own making, one's own self and something alien to oneself. Alienated things, situations, or actions always involve one's own performance, or, as we shall see in the case of emotions, one's own feeling or expression-it's just that this ownness, the possibility or means of appropriation, somehow gets lost or becomes unavailable in a sense yet to be specified. Lastly, alienation is always a three-dimensional relation: it is a relation of relationlessness at once to oneself, others and the world. As I shall show in the next section, this three-dimensionality becomes particularly salient if we consider emotional self-alienation.

At this stage, however, we seem to face a paradox when conceiving of alienation as involving a deficiency in the quality of our self-, other- and worlddirected relation. Emotions, as explicated in more detail below, are not some inner bodily states (even though bodily feelings often accompany garden-variety emotions, such as fear, anger, etc.). They are essentially relational or intentional. 
And emotions are relational in precisely the three-dimensional sense of alienation: they are at the same time expressive of oneself, disclosing something that matters to oneself, thus intentionally presenting worldly occurrences or others as having a certain value, and, by dint of their very (self-)expressive nature, they typically relate us in specific ways to others. Now, the initial paradox presents itself thus: if alienation is a relation of relationlessness to oneself, others and the world, and if emotions are essentially self- and world-related, how can one ever be alienated from, and least of all feel alienated from, one's own emotions? In the next section, I aim to show that, emotions and self-alienation properly conceived, there are three different conceptions of the phenomenon of emotional self-alienation that do not lead to straightforward paradoxes, but rather illuminate something important about the way we emotionally relate to ourselves, the world and others.

\section{What Emotional Self-Alienation is Not: Manipulation, Coercion, and Self-Deception}

Before elaborating on the three non-paradoxical senses in which someone might feel alienated from her own emotions, let me address a fundamental ambiguity in the very locution 'emotional self-alienation'. There are two different readings when juxtaposing the terms 'emotional' and 'self-alienation'.

(a) On the one hand, one might think of complex processes in which, by having certain emotions, one feels momentarily or robustly alienated from prior life-projects, from one's own 'self-here one cannot properly relate to one's initial self-image ('I don't recognize myself; 'This is/was not me.')—from other people ('Others seem alien to me.'), or from the world or 'reality' ('I've lost touch with reality.'). This might be the case for example due to existential crisis, psychopathological changes in affective disposition (e.g., in depression or phobias) or, less dramatically, newly acquired emotional experiences or dispositions (e.g., loving someone whose behaviour or values one cannot identify with or integrate into one's previously held evaluative outlook). It is this notion of affectively, and often psychopathologically, induced more or less pervasive estrangement that some authors have investigated in terms of an "existential change" or "an allenveloping shift in one's sense of 'belonging to a shared world"' and in one's relation to other people (Ratcliffe 2015, 14; see also Slaby et al. 2013). ${ }^{2}$

\footnotetext{
2 Though the term 'emotional self-alienation' should prevent respective misconceptions, it might still be useful to warn against mistaking an analysis of ESA more generally for how to account for affectively or non-affectively induced feelings of alienation, or what it feels like to live or work under certain socio-economical, cultural, etc. conditions of alienation. This has so far been little scrutinized; see however in Heller 1979, Part II.
} 
(b) But there is another, narrower reading of 'emotional self-alienation', and this is the one I shall be exclusively concerned with here. According to this reading, emotional self-alienation concerns not alienation from oneself and one's initial existential embeddedness in a (shared) world, by virtue of certain emotional experiences or affective dispositions, but rather alienation from one's own emotions. In the sense of ESA I wish to explore, one feels alienated from one's own emotions. But to get a grip on what this means, we must clearly delineate this feeling from a number of cognate but different phenomena.

First, it seems natural to assume that ESA would entail feelings of being affectively and/or cognitively manipulated. True, some form of affective manipulation will typically initiate or result in ESA. Moreover, in ESA, one might and indeed typically will have the feeling of being manipulated. Yet, ESA is certainly not identical to and does not necessarily entail such a feeling. Even if one feels manipulated when one feels alienated from one's emotions, the latter is not identical to what it is like to be manipulated. After all, I might well feel affectively manipulated, say by political rhetoric, in having come to hate certain political opponents or by subtle motivational triggers in looking forward to seeing the next episode of my favorite TV-series. This might even be the case were I to identify with my anger or 'own up', as it were, to my delight. Admittedly, in paradigm cases of affective manipulation, and especially in what I call 'emotion invasion', feelings of being manipulated will result in ESA and obstruct the appropriation of one's emotions, but the systematic phenomenological point still holds: the very experience of feeling manipulated such that one ends up having a given emotion $E$ and of feeling alienated from $\mathrm{E}$ are not identical.

Similar considerations apply to external forms of heteronomy and coercion. The issue in ESA is not that subjects feel by some heteronomous powers coerced to have certain emotions-be these coercive powers internalized, but heteronomous desires, akratic behaviour or doxastic akrasia (cf. Szanto 2017a), or some external triggers, etc. If this were at issue, the distinctive experiential characteristic of the phenomenon would simply disappear. Consider that alienation involves a deficient relation to oneself (and others and the world). But in clear-cut cases of affective heteronomy the relation does not concern some deficiency between me and myself, but between me and something alien to me, or some specific other, viz. something that clearly stands opposed to me. By 'clear-cut cases' I mean those in which the affective and epistemic boundary between what I feel to be mine and what I explicitly acknowledge or (pre-reflectively) understand to be thus and that which I clearly do not own-and do not wish to own or feel capable of owning in the first place-is well preserved. 
Accordingly, a key to understanding the phenomenology of ESA lies in appreciating its inextricable dialectics of owning and disowning emotions. In ESA, it is oneself that owns the given emotion; it is oneself feeling the emotion in the sense of experiencing, expressing or enacting it. At the same time, it is not oneself feeling it in the sense that one is not properly affected by what one feels or experiences. I will come back to this point. For now, keeping this dialectics of identifying-with and not identifying with what oneself affectively experiences should suffice to demarcate proper instances of ESA from seemingly similar but different forms of heteronomy. Jaeggi aptly captures this difference between (self)alienation on the one hand and coercion, pretense and deception on the other:

In both coercion and deception the boundary between what is one's own and what is alien is preserved; [in phenomena of inauthenticity], in contrast, there seems to be a complicated entanglement of the two where what is "one's own" itself becomes questionable or deficient. (Jaeggi 2005, 71; cf. also 53-54, 58, 70)

But one might wonder whether in contradistinction to what I have called 'clearcut' cases of internal or external heteronomy there might be 'non-clear-cut' cases that would amount to ESA. By non-clear-cut cases, I am thinking in particular of self-deception. Though ESA might easily be confounded with self-deception, we have to distinguish it both from doxastic self-deception due to emotional biases and from properly speaking emotional self-deception. Consider first doxastic selfdeception. Proposals for how to account for self-deceptive belief are legion, but according to one standard conception it entails the following: a subject $\mathrm{S}$ has reason to believe $p$, acknowledges that her warrants for $p$ are stronger than those for $q$, acknowledges that $p$ and $q$ are incompatible, and yet forms or maintains the belief that $q$. In short, the self-deceptive believer believes something in the teeth of evidence to the contrary. Now, there may be many, if only irrational, reasons or a-rational motivations for such forms of irrationality, including emotional or affective biases (cf. Mele 2001; Szanto 2017a). We have some deficient selfrelation involved here, and it is also true that often this deficiency results in ESA. However, nothing speaks for equating such affectively induced forms of irrationality with ESA. First of all, according to most standard accounts, ordinary selfdeception is a form of motivated irrationality. It typically entails an intentional or deliberate procedure; one brings oneself to form self-deceptive beliefs. This is markedly different in self-alienation. After all, one of the distinctive characteristics of self-alienation is a certain heteronomy, which involves a loss or at least a sense of lack of control over oneself. Secondly, what is deficient in self-deceptive beliefs is the relation that one has towards one's beliefs. Even if they involve beliefs about oneself, and even if these beliefs are affectively biased, what is at stake here is my relation to my beliefs and not my emotions. 
This is of course different in self-deceptive emotions (SE). Assuming the structure of doxastic self-deception, it is not immediately clear how we should conceive of SE, without ending up with outright paradoxical formulations (which, as a matter of fact, also haunt most descriptions of doxastic self-deception). One possibility would be to say that SE occurs if one has sufficient reason to believe that one experiences an emotion E, but — due to some set of values, beliefs, moral or normative stances, which make it seem undesirable or wrong for the subject to have $\mathrm{E}$-one makes oneself believe that one experiences another emotion $\mathrm{E}^{*}$ or no emotion at all. However, the deficient relation to my emotions here is still a doxastic relation: I make myself believe not to have emotions that I experience. But again, isn't it a form of dis-identification or self-distancing that we are seeking? All depends on how exactly we cash out the very process of dis-identification here. If it were an affective process, whereby in some yet to be specified sense, I feel distanced or dis-identified from my own emotions, we would have ESA. But this seems not to be the case here: in SE, the process of dis-identification stems from a gap between what I, according to some set of values or some normative self-conception or self-image, want to be, and what I in fact feel. I eventually seek to close this gap by a doxastic process, namely a self-deceptive belief about my emotions. Properly speaking, however, I don't feel alienated from my emotions. Rather, in having an emotion, I feel alienated from my desired self-image, and try to intervene by self-deceptive belief formation.

Still, one may argue that there are cogent forms of self-deception that in fact show all the signs of a deficient affective relation to oneself, characteristic of ESA. One such form is a certain emotional inauthenticity famously analyzed by Sartre in terms of what he calls 'bad faith' (mauvaise fois). ${ }^{3}$ In fact, in some formulations, Sartre's bad faith represents a conception of emotional self-deception that closely resembles ESA. However, as I want to show, it is still not quite the phenomenon we are looking for.

As the notion somewhat misleadingly indicates, bad faith is a negative attitude towards a belief, i.e. a doxastic attitude, albeit a special one. Bad faith is a form of lying to oneself, a lie to oneself about the structure of one's own existence. But what is it that the subject lies about in bad faith? According to Sartre, the false belief planted in oneself is not so much about worldly events, states of affairs, character traits, or specific emotions, but about one's ontological selfunderstanding and self-relation. Bad faith is an existential lie about one's very being or the basic nature of 'human reality' (or Dasein) itself. For Sartre, human reality is characterized by the pervasive freedom to choose oneself and to endorse, at any

\footnotetext{
3 We find another account, also from the classical-phenomenological tradition, in Scheler's discussion of emotional self-deception (Scheler 1919). I come back to that in sec. 4.
} 
time, one's ever-open possibilities. In bad faith, one negates one's own spontaneity and freedom. But it is not just up to oneself to do so. Bad faith is not merely a contingent, deviant form of self-relation but an essential, albeit non-authentic, mode of being. Bad faith discloses the intrinsic negativity of human reality by means of which one constitutes oneself as not being what one is or as being what one is not, to put it in Sartre's paradoxical formulation. One identifies one's own human reality (Being-for-itself) with the reality of objects (Being-in-itself). Bad faith then is grounded in human reality's proper existential-ontological structure. It is a pervasive existential attitude of self-negation and self-reification.

What happens now if one thus negates affective states one has, or is in bad faith about a desire or emotion one has? Sartre gives an out-dated if not chauvinistic example of a woman who agrees to a date with a man who is apparently attracted to her, a fact she very well acknowledges. Although she seemingly reciprocates his desire and intentions, she cannot, or wishes not to, integrate those desires into her self-image as a respectable woman. While aware of the delicacy of the situation when he reaches for her hand, which would call for an "immediate decision", instead of owning up to the decision, "she does not want to realize [its] urgency $(. .$.$) that is, she does not want to see possibilities (. .$.$) which [the man's]$ conduct presents" (Sartre 1943, 55). The important point for our present purposes is that Sartre conceives of this (self-)denial as a phenomenon we have already encountered above: a failure to integrate affective states into one's selfconception. The deficient relation to oneself is again not so much a deficient affective relation to one's affective states but a deficiency in the coherence of what one wants or desires and what wants to be. The deficiency is due to the fact that "she does not quite know what she wants," Sartre tells us (ibid.). This deficiency then results in a motivated, self-deceptive blurring of one's own desires and eventually in the reification of one's (bodily) desires as not belonging to oneself. Instead, according to Sartre, one would need to recognize one's personal, or existential freedom: "In order to satisfy her, there must be a feeling which is addressed wholly to her personality - i.e., to her full freedom — and which would be a recognition of her freedom." (ibid.) But this is exactly what she fails to do.

Sartre's reference to the feeling not being "addressed to the whole personality" is on the right track. As we shall see (sec. 4) the deficient relation to precisely that aspect of feelings that involves one's overall personality is indeed one of the key features of ESA. Still, the process of self-negation in bad faith, as Sartre conceives of it, is not so much a form of self-alienation, for neither the dimension of 
self that is negated here (one's freedom to choose) nor the desire one veils from oneself is something alien to oneself. ${ }^{4}$

Regarding the last point concerning desires, a further qualification is in order. One might be attracted to the idea that ESA entails the sort of self-alienation one may indeed feel when one cannot identify with one's own desires. Suppose a staunch pacifist, who regularly participates in rallies against the Second Amendment, suddenly discovers at an NRA-arms-fair his fascination for heavy air rifles, which eventually grows into a secret passion. Here, even though the relational structure of alienation from one's own desires very much resembles emotional self-alienation, we must distinguish the case for the following reason: though desires may involve some overall personal concerns, which is also characteristic of those emotions from which one may feel alienated, they lack a clear-cut distinction between the intentional object and the affective focus that is characteristic for emotions. However, since an important part of my analysis of ESA will draw on precisely this distinction we need a separate analysis of the phenomenon, one that I cannot engage in here (for a convincing analysis, see Jaeggi 2014, 104-119).

One final caveat is in order before we can get a handle on what ESA actually is. Similar to the potential deficiency in identifying with one's desires, recalcitrant emotions and disruptions due to emotional self-deception, ambivalent or outright conflicting emotions will not necessarily lead to ESA. That somebody, for instance, harbors resentment and, at the same time, admiration towards a person, or cannot resolve an emotional conflict between the disappointment of not getting a job in a foreign country and being relieved about being rejected because she doesn't want to leave her family behind, does not mean that this person feels alienated from her own emotions. Again, enduring ambivalences and conflicts of this sort might often result in the experience of ESA, but they need not. One might also 'own up' to both emotions and ensuing 'affective gaps' within oneself, and accept such emotional incoherencies without feeling alienated from either of the given emotions.

\section{Three Dimensions of Emotional Self-Alienation}

What then is ESA? As we have seen, on the narrower reading I have suggested above, ESA initially means that one feels alienated from one's own emotions. Recall that I have contrasted this with feelings of alienation from one's own projects, life, self, others or the world, maybe in virtue of some affective disturbances, such as depression or otherwise. In the following, I want to analyze the narrower mean-

${ }^{4}$ Here, I partly disagree with Jaeggi, who interprets Sartre's bad faith as a form of self-alienation; cf. Jaeggi 2005, esp. 19-20 and 91-92. 
ing of ESA in terms of three different but interrelated dimensions of what it means not to-or, better, not to appropriately or to deficiently - feel one's own emotions. Observe that I take ESA to entail a deficiency in feeling one's own emotions, i.e. a deficient affective self-relation, and not a deficiency in lacking the affective or 'feeling' dimension of emotions or lacking certain emotions altogether. I take extreme cases of not feeling anything (relative to certain situations, persons, events, etc.) or not having emotions altogether not to get at the core of ESA. Such extreme forms of not feeling anything at all might arise in severe depression (Ratcliffe 2015) or existential-ontological deficiencies in affective "attunement", or what Heidegger characterizes as a "slipping away from ourselves", an "emptiness" or a "leaving ourselves behind in abandoning ourselves to whatever there is" in "profound boredom" (Heidegger 1929-30, 119; cf. Slaby 2010). To be clear, such deficiencies might well amount to forms of ESA, but not in the sense I wish to explore here, namely of not appropriately feeling one's own emotions.

To be sure, everything hinges upon how precisely to conceive of what 'not properly' or 'deficiently' means here. As we shall see, what I certainly do not want to suggest is that the adequacy condition here has anything to do with some sensational components or some kind of intensity of (bodily) feelings. Rather, it has to do with the following three components: (1) the clarity of the affectiveintentional focus of emotions; (2) their self-revelatory or self-disclosing dimension, and finally (3) the normativity of emotions, or the appropriate relation between one's experiencing, regulating and expressing an emotion, on the one hand, and the (extrinsic) norms of emotions, or feeling rules, on the other. According to these three dimensions, genuine cases of ESA entail either one or all three of the dimensions. Thus, any of these dimensions may occur independently or weigh differently in ESA. Typically, however, since they are variously interrelated, they will be manifest in tandem and indeed reinforce each other. In any case, whenever one or another of these dimensions is deficient, we will have to say that the given subject is (affectively) not identifying with or fails to 'own up to' her own emotion. And it is this non-appropriation that is also expressed by the notion of not 'appropriately' feeling one's emotions in ESA.

Consider, then, the following senses in which one might be said to not appropriately feel one's emotions:

(1) not appropriately feeling what one feels

(2) not appropriately feeling what oneself feels, but rather what 'one's Other' or others feel

(3) not appropriately feeling what one ought to or supposedly could feel 
As should be obvious, these three senses refer to three dimensions of emotions: their affective and experiential, first-personal, and normative dimensions. At the same time, they refer to three deficient relations of a subject of a given emotion to her feeling that emotion. Let me now explicate these deficiencies in turn.

(1) As already mentioned, not appropriately feeling one's own emotions does not mean that one does not feel one's emotions intensively or somehow 'deeply' enough. ${ }^{5}$ ESA has nothing to do with purely affective, sensational or experiential intensities. Instead, I now want to argue that it concerns the blurring, dissociation or the complete gapping of two essential-and, in appropriately felt emotions, essentially intertwined-dimensions of emotions, namely their affective and intentional dimensions. My thesis is that ESA is a deficiency in how a subject tares the balance between these two dimensions. Thus, contrary to appearances, though ESA is a relation of relationlessness that crucially involves the self, it should not be conceived in some internalist fashion, as if ESA were merely an experiential deficiency in subjects. Rather, it concerns the complex relation that a subject entertains regarding the objects of her emotions, understood as felt intentional evaluations of those objects. And this seems to be just the right consequence, given that I have characterized (self-)alienation as a relational process that involves not just the self but always equally the world.

To understand this better we need to introduce some conceptual distinctions. I will draw on the vocabulary developed within the affective intentionality paradigm (Slaby \& Stephan 2008), and notably by Peter Goldie and Bennett Helm. According to this influential, and in my view most convincing contemporary account, beyond a number of other components (expressive, bodily, regulative, etc.), emotions have a specific intentionality that picks out a given target in a way that equals no other intentional or mental state (such as belief or desire). An irreducible component of the very intentional directedness of an emotional experience is its affective content. Thus, emotions are psychological states that are not just intentionally but, at the same time, affectively directed at their intentional targets. According to a well-known construal by Goldie, they are distinguished by subjects" "feeling towards" their emotional targets. Feeling towards is a "thinking of with feeling" $(2000,19)$, i.e. a special way of thinking of a given object that is radically different from how ordinary intentional thought presents its objects. The very intentional content of, say, fearing something is different from merely perceiving or thinking of something as dangerous. Suppose I'm cycling down a winding mountain road with high speed towards the next curve. In 'thinking of the curve it 'with feeling', I not only perceive and cognitively grasp the danger, I

\footnotetext{
${ }^{5}$ Below, I come back to how ESA does indeed affect emotional 'depth', albeit in a different sense of the term than experiential characterizations capture.
} 
am afraid of it. The next day, thinking of the event safely passed, I still aknoweldge the dangerousness of the situation and may be angry with myself for having been incautiously fast. However, I no longer feel the danger. I think of the curve as dangerous, but I'm not thinking of it with feeling. (Goldie 2000, 19, 589). In emotions, the 'thought' presents the given object as having an affective import for the subject. Without being some "add-on" to the 'thought', thinking of with feeling picks out the affectively salient and relevant properties of a particular object, namely those that matter to the subject.

On a congenial view put forth by Helm, this feeling towards aspect is characterized as a "felt evaluation" (Helm 2001, 29-41; 2009, 49-74). Emotions, understood as felt evaluations, are directed at certain evaluative properties of an object. The intentional target of an emotion is the evaluative property of the object that has (affective) "import" for the subject. To specify the way in which the evaluative properties of an emotional target have import for the subject and make intelligible the relation that those evaluative properties bear to a particular object, Helm introduces the notion of the "focus" of an emotion. We need to make this relation intelligible because one cannot readily read off the evaluative property in focus simply by looking at the (type or token of) emotion at hand and the targeted particular object. Accordingly, the focus can also be characterized as the implicit "background object" of the emotion (Helm 2009, 58). The target and the focus of emotions do not necessarily coincide. To illustrate: my fear that somebody may break into my house while I'm on holiday and steal my irreplaceable vintage bike, and my furious anger at the bicycle repairman, who, due to utterly careless handling, damages its pristine chrome-frame, have different objects and are different types of emotions (viz. fear of robbery and anger at the experienced repairman's carelessness). But my emotional focus is identical here (the import that the bike has for me), and this, not the type of emotion (anger, fear), is what individuates the target of an emotion. It is also in light of the focus, namely the import that my bike has for me, that makes both my fear and anger intelligible. And there is more to the way an emotion's focus targets an object as having personal, affective import. Crucially, the intelligibility, and indeed rationality, of a given emotion depends on the evaluation of its target being warranted or not. The focus of emotions, understood as "feelings of import", does not only make the import salient, it also carries normative powers (cf. Helm 2009, 58). Moreover, it represents the standard against which a given emotion can be assessed as appropriate or not. Thus, my furious anger at the repairman would be unwarranted and hence irrational if I were not to care about my bike at all, and it would be equally inappropriate if the damage to the frame were so minimal that it was hardly visi- 
ble to the bare eye and had no influence whatsoever on the impeccable functioning of the bike.

Emotions, then, are "a kind of sensitivity or responsiveness to the import of one's situation: emotions are essentially intentional feelings of import" (Helm 2007, 58). Emotions, as a form of sensitivity to import, are affective; as evaluative of objects of import they are intentional, and as responsive to import they are subject to norms and warrants. Emotions, as intentional feelings of import, are affective, intentional and normative at the same time. Below, we will see how this point about the normativity of emotions carries over to the third sense of ESA, according to which one is not appropriately feeling what one ought to or supposedly could feel. For the moment, let's concentrate on the affective and intentional dimensions and on how they come apart in ESA.

I want to argue now that in ESA the focus of an emotion becomes blurred and the subject eventually loses the sensitivity to the import of one's own emotions. More precisely, the sense that something has personal import for me gets lost. In self-alienated emotions the sensitivity and personal import become pale or vanish completely. When someone is not appropriately feeling what one feels, what wanes is the feeling of personal import of one's emotions. But are selfalienated emotions still emotions then? Recall that I have defined emotions in terms of their affective intentionality, or in Helm's terms as intentional feelings of import. Self-alienated emotions are still felt and they are still intentional. They are felt in the sense that they are experienced as evaluations one has or has had formerly; but they are not felt in the sense of mattering to or affecting oneself. And, as evaluative stances, they are still properly intentional. They are still directed at some target object. But what becomes blurred is the emotion's focus, the dimension that relates the evaluative property of the target to the import that the object (supposedly) has or has had for the subject.

To be sure, notions such as the 'blurring' of the affective focus or the import's 'becoming pale' are not only metaphorical, but also essentially vague, admitting of fine-grained nuances. And this reflects the process quite well. For whether we have a case of someone not having any access to the evaluative focus and eventually not feeling any import at all or losing all sensitivity to affectively responding to it, or whether the import becomes of no overall personal concern, yet still has some pale effect on the subject, will be a matter of situative differences. In either case, however, the crucial point is that, when someone feels alienated from her emotions, it is the emotions' import, in the sense just specified, that is deficient.

But this is just one side of the story regarding the cleavage of the two dimensions, i.e., the affective and the intentional. Emotions are intrinsically affec- 
tive and intentional, and one dimension is not just an "add-on" to the other (Goldie 2000); they are intrinsically interwoven. Self-alienated emotions not only do not affectively impact the subject. Conversely, there is also a deficiency on the part of the intentionality or the evaluative dimension of the respective feelings. This is because the properties that the intentional feelings evaluate no longer match with the (overall or contextually relevant) evaluative outlook of the person.

Let me exemplify this with two different cases of ESA, stressing the different sides of the affective-intentional gap in ESA. First, slightly altering the example of the staunch pacifist who develops a secret passion for rifles and war-games, suppose that he is still (negatively) appraising them according to his still dearly held moral and political convictions. But both these and his appraisal have lost their affective grip on him; he might still feel some repugnance or even disgust towards the martial display of his own and/or others' affects. At the same time, he feels that it is these affects - and not his repugnance or disgust - that relate him more appropriately to his target (the games, rifles, etc.). He has, then, lost his initial relation to his evaluative target; he bears a 'relation of affective relationlessness' to it. Conversely, his halfway self-confessed blind admiration for a starplayer in his favorite ego-shooter game is not compatible with his still firmly upheld, overall evaluative outlook on violence or war-games. ${ }^{6}$ Or take a flight attendant who not only delivers comforting smiles and constant charm to passengers and her colleagues but, unable to attend to her own emotional dispositions and moods after years of service, also displays a diffuse and soothing cheerfulness at home with her partner and children, even if the housework becomes unbearably straining. While she thus navigates changing situations with her invariable emotional expression, her affective malleability to the varying affective import of given situations and interpersonal encounters becomes rigid. She loses the appropriate affective responsiveness to her environment as well as to her own affective sensitivity.

The cases differ not only regarding which of the two dimensions of emotions is deficiently related to oneself; they also differ as to the causes of these deficiencies. While the pacifist is subject to ESA due to his own failure to calibrate his affective and evaluative focus according to his changing affective dispositions, the flight attendant and her fellow emotional laborers in the service industry are subject to what I have called emotion invasion. Here, the cleavage results from the fact that others, social media, companies, etc., implicitly or explicitly make persons attend only to specific functional aspects of emotions, and typically to their expressive or emotion-regulative dimensions, and make them ignore their

${ }^{6}$ Notice that this is not a problem of not being able to identify with his desires or affective dispositions, which led him to have these emotions in the first place; see above, sec. 3. 
evaluative, feeling dimension. Eventually, this ignorance becomes habitualized and the person turns herself her own initially felt evaluations into mere functional appraisals or mere expressions of evaluations.

To summarize the findings so far: ESA in the sense of not appropriately feeling one's emotions either means that one's felt intentional evaluations are not felt, in the sense that they don't affect or impact one personally, or that one cannot integrate the values thus targeted, or appraised, into one's overall evaluative outlook. In either case, we see that there is a cleavage between the affective and intentional dimensions; at the same time, we have a deficiency in how either or both of those dimensions impact or are appropriately related to me or, more precisely, to my affective sensitivity, my responsiveness to (my) values, or my overall evaluative outlook.

(2) At this point, we have to turn to the second sense of ESA: 'not feeling what oneself is feeling', the sense in which ESA exhibits a deficient relation or a certain relationlessness to the self. In elaborating this sense, I want to bring into relief an idea that I have already hinted at repeatedly: the idea that in ESA emotions do not impact or affect the very person who has them. My claim is that this deficiency concerns a deficiency in the self-revelatory or self-disclosing function of emotions.

To understand this, we have to say a word about the relation of emotions to the self. As a number of authors emphasize, emotions are self-involving in a richly specified sense. This goes well beyond the sense in which many emotions, "emotions of self-care" as Pugmire calls them (2005, 101), directly involve the self: for example shame, pride, remorse or embarrassment. The self-involving character I have in mind here concerns a fundamental web of relations that emotions generally bear to the self. Even if not all emotions are about the self, and the self is not always "on the stage", the self is always "present as the stage" of emotions (Pugmire 2005, 100). What exactly does that mean? First, whatever is in view in and through an emotion is something that is in view from a distinctively first-personal vantage point, or what Goldie (2001) calls a "personal", as opposed to an "impersonal", point of view. Emotions are necessarily such that they can only be experienced from one's own point of view (cf. Slaby \& Stephan 2008). ${ }^{7}$ But emotions are not just experienced from a personal point view; they also represent such a view, both to myself and to others. When I or others think or talk about emotions, we typically employ personal pronouns or proper names. This is not for merely trivial grammatical reasons. Rather, we want to mark what I, or she or he was feeling on a given occasion, not what anybody could or would have

${ }^{7}$ Notice that I do not take this to preclude genuinely shared emotional experiences, see Szanto 2015, 2017, León, Szanto, \& Zahavi forthcoming. 
felt. Moreover, as Goldie and others emphasize, emotions "are embedded in and interweaving with the rest of the person's emotional life and other aspects of his mood and character" (Goldie 2001, 16). They are only comprehensible to oneself and others by placing them over and against a more complex and enduring "rational pattern of felt evaluations" (Helm 2001) that form the fabric of which persons are partly made. In understanding that I was no longer jealous because my love was already waning I understand something about the person I have become. In understanding that it was not an irrational overreaction that she became so furious at him despite his seemingly innocuous remark, because I learn that she was deeply hurt by his similar remarks made repeatedly before, I understand something about her personality and personal history.

Emotions, then, do not only convey my or your evaluative perspective; they also always convey something about me or you. This, in essence, is what it means that emotions "contain an ineliminable reference to the self" (Nussbaum 2001, 52). And this is not a mere referential or epistemic relation. Emotions don't convey value-neutral information about a person. They bear an axiological relation to the self, conveying information about what matters for one's wellbeing or contributes to personal flourishing. Here is how in his inimitably elegant phrasing Pugmire expresses this point (for a similar view, see Nussbaum 2001, 30-33):

some of the things I recognize to be important do actually concern me. Among these, perhaps foremost among them, are the things I have 'made my own'. That is, certain things become incorporated as conditions of my well-being while others are left to languish in the conative cold. (...) The result is a personalized ordering of the world in which things matter according to the part they can play in my flourishing (or lack of it). (...) We then keenly appraise events as they impinge on the articles of the world's furniture we have so artfully arranged into our personal sanctuary. And these are the appraisals that stir us to emotion, draw us out from the sidelines. (Pugmire 2005, 102)

Now, the focus of emotions involves both an exposure of objects and events of value and self-exposure. It takes in view what matters to me in a given moment, not just in objective time but rather in the context of my life and personal flourishing. ${ }^{8}$ The focus is an affective focus because our appraisals are not mere intentional judgments, but "made our own". They are made our own if their affective

\footnotetext{
8 This should not be misunderstood as if ESA was a punctual or momentary phenomenon. Quite the contrary: ESA can only be understood as a form of self-alienation, once the subject of ESA acknowledges her own previous evaluative stances or places a given emotion into the context of one's diachronically robust evaluative outlook. Incidentally, here we have another difference to so-called 'straight' cases of self-deception (Mele 2001), in which someone holds a false belief $p$ at $t$, while acknowledging contradictory evidence to $p$ at $t$.
} 
impact "draws us out from the sidelines". And emotions fail to do so, I argue, when we are alienated from them.

In particular, I want to argue that in ESA emotions do not (fully) disclose what they otherwise do, namely the evaluative perspective of the person who has them. Again, this deficiency has to do with the blurring of the affectiveintentional focus of emotions. The blurring of what's in view via the affective dimension of the focus is accompanied by a lack of personal investment in, or commitment to, the evaluative perspective that the emotion offers. One lacks such affective investment if one is unwilling or unable to really adopt or follow up on the given evaluative perspective. One may still see the object in the light of an evaluative perspective. Alienated emotions need not lose their evaluative function as such. But one feels at the same time that the given perspective is precisely not one's own. Accordingly, "the conception of emotion as keyed to the personal incorporation of its objects" (Pugmire 2005, 103) shifts to a conception of emotion as a mere evaluative judgment. Lack of emotional appropriation here then means that the object of the emotion is not incorporated into a person's overall evaluative perspective. The given evaluative perspective cannot be integrated into one's overall evaluative outlook because the evaluative properties of the intentional object are not appropriately targeted: they are not in focus'. ${ }^{9}$ Conversely, the overall evaluative outlook no longer matches the actually felt emotions. This, however, is not due to some cognitive or reflective failure ${ }^{10}$ but to the lack of affective commitment.

This is precisely what happens to our pacifist, who fails to incorporate his actually felt intentional evaluations into his previously held evaluative outlook. He might still be cognitively committed to his moral and political convictions, but he has lost affective attachment to them and his 'former self, upon whom they have ceased to exert affective powers. At the same time, he still feels, in whatever inchoate ways, committed to that former self. The self, then, that is now affectively impacted by war-games rubs against the self in which war-games were precisely not incorporated, but rather foreign objects. Thus, his repugnance to his actually felt evaluation (his admiration for the star-player) "fails to embody" his affective commitment to the object, or is "not keyed to" it. Accordingly, the web of those

\footnotetext{
${ }^{9}$ Here, my account is similar to but relevantly different from Brewer's, who cashes this out in terms of a 'refusal' of 'acknowledgement': "Emotions might be alien either in an objective sense or in a subjective sense. Objectively, emotions are alien when they express the evaluative outlook not of the person in whom they arise but rather of some other agent. Subjectively, emotions are alien when the person in whom they arise refuses to acknowledge the evaluative outlook embedded in them as his own" (Brewer 2011, 275). See more on Brewer below.

${ }^{10}$ It bears stressing that one need not be explicitly or reflectively aware of an affective evaluation as being one's own in order to feel alienated from it. On self-reflective alienation, cf. Moran 2001, esp. 33-34.
} 
emotions that he now has does not form a rationally coherent pattern. And they don't cohere rationally not because of some cognitive deficiency, but because the underlying commitments don't form an affectively sound pattern.

In this way ESA disrupts what Pugmire explores in terms of "emotional depth", the "soundness" or "integrity" of emotions. Notice again that emotional depth is not a matter of experiential intensities or strength of (bodily) sensations. Rather, as Pugmire convincingly argues, it is primarily a matter of "how much [emotion] reflects (or achieves) an underlying alignment of the body of the person's concerns" $(2005,42)$. It is a matter of overall "embeddedness" in the diachronically robust web of a person's concerns, and ultimately her "life", and can only be measured holistically, by “the degree of embedding of an emotion's proximate ground in the whole field of one's concerns" (ibid., 43). Though this is a subjective dimension of emotional depth, it should by no means be understood internalistically, as if embeddedness were only a matter of intra-personal coherence. On the contrary, Pugmire rightly argues that intra-personal embeddedness must be supplemented by external and relational criteria in order to account for depth.

Here appropriateness in terms of external grounds and warrants for emotions comes into play again. Emotional depth depends on the coherence between what affects me personally and what affective reaction a given worldly situation "calls" for: "I can only be too unaffected in relation to what is actually called for, i.e. to some standard of how affected I need to be in the situation which is external to how affected I am", and hence "part of what decides the weight of an emotion lies beyond the emotion in the world at which it is directed" (ibid., 50, 51). Thus, in ESA, emotions not only lose their function to register what has import for me but the targeted objects also lose their status as grounds and warrants for my evaluative stances.

We find a congenial point from the early phenomenologist and value-realist Scheler in a little-known passage in his essay on self-deception, where he considers self-deceptive illusions regarding one's own emotions. Scheler claims that such illusions are due to an erroneous internalist reversal of the intentional directedness of emotions:

we can also see in the field of values and their relations to feeling and to the objects of feeling a (...) natural direction of deception (Täuschungsrichtung): The feeling of a person is initially straightforwardly directed upon the values which adhere to objects; and that to an extent, that she tends to overlook her own emotive reaction to the value, her being "delighted" about something, her being sad about something; or, in contrast, tends to transfuse (aufprägen) the quality of the value, due to which that emotive reaction arises, upon her emotive reaction. Thus, not empathetic projection of one's own feelings into the object and their values (Einfühlung von Eigen- 
gefüblen in die Sache) is the primary direction of deception, but rather the very opposite of this phenomenon, namely the transference-from-outside-to-the-inside (Vonaußen-nach-innen-Verlegen) of felt (...) value-qualities of things and situations into the sphere of feelings of one's own egoic states (Ich-zustände). (Scheler 1919, 262, own translation)

This reversal, or suspension, of the intentionality of felt evaluation eventually leads to the emotion being experienced or felt inappropriately (auf unechte Weise), or as a "shadow" of itself (ibid.). Hence, it is precisely the loss of focus on external warrants, i.e. upon the object's value-properties conveyed by the felt evaluation, that renders the very affective dimension of emotions pale; it is not the loss of some unspecified intensity of bodily feelings or inner sensations that has this effect (cf. ibid. 263f.).

Now, given the self-revelatory role of emotions, it should be easy to see what happens if ESA becomes a habitualized feature of one's affective life or if one becomes robustly alienated from one's emotional sensitivity. If one's emotions robustly lose their evaluative responsiveness, ESA hampers what Brewer calls the "self-elaboration of person". Self-elaboration is rendering transparent one's initially indeterminate and "inchoate" "evaluative outlook" (Brewer 2011, 289). This can only be achieved precisely by emotions, for it is emotions that "give expression to the self's pre-reflective evaluative posture towards the world, and they provide crucial raw material for the lifelong task of working up this initial posture into a mature and discerning outlook upon the values in play in our changing circumstances" (ibid., 275). Emotions have this dual aspect: expressing a subject's evaluative stance and individuating values for her. In doing so, they elaborate what matters for oneself. Rendering one's emotions transparent and articulate, one simultaneously performs the work of self-elaboration. "When we try to get straight on what we feel, then, we do not face two separate tasks: to make our evaluative stance articulate and to clarify whatever values are in view. These are at heart the same task-the task (...) of self-elaboration" (ibid., 288). And Brewer rightly maintains that emotional alienation is just that: a disruption or disfiguration of this never fully accomplished task of self-elaboration. A robustly emotionally alienated person would then not only be episodically uninvolved and unaffected, but ultimately remain immature.

The deficient articulation of the self in ESA is also displayed when it comes to emotional expression. This becomes particularly vivid in representatives of emotional laborers in the service industry, such as flight attendants. In Hochschild's fitting capture, flight attendants see their ever-required smiles as an "extension of the make-up"; like literal make-up, "they are on them, but not of them" (Hochschild 1983, 8). This would not be so remarkable were such 'self-void' 
emotions only episodic features of ordinary, deliberate self-presentation or roleplaying (Goffman 1956), or of so-called "surface acting". However, it becomes a more pervasive and more perturbing feature if the expression of such emotions, devoid of their self-disclosing function, is performed by "everyday deep acting" (Hochschild 1983, 37-48). This happens if subjects unwittingly enact emotions according to conventionalized, socioculturally prescribed or even corporately codified and enforced "feeling rules" (ibid., 56-75). Feeling rules police and possibly sanction not only the form and appropriateness of emotional display (e.g., to enhance the quality and the profit of customer-service exchanges), but also "the extent (one can feel 'too' angry or 'not angry enough'), the direction (one can feel sad when one should feel happy), and the duration of a feeling, given the situation against which it is set" (Hochschild 1979, 564). Thus, they deeply modulate the very content and phenomenology of emotions. And they often become internalized and embodied in ever-repeated social practices and (corporate) rituals, eventually sedimenting themselves in a more or less rigid, alienating "emotional habitus" (Illouz 2007).

(3) At this juncture, with the introduction of the notion of alienating feeling rules, we must finally turn to the third dimension of ESA: the sense in which one does not feel what one ought to or supposedly could feel. We have already seen how the normativity of emotions plays out in the affective-intentional dimension of emotions, and in particular concerning the appropriateness of the relation between their object and focus. Here I want to investigate the disruption of normativity with regard to the appropriateness of the relation between experiencing, expressing and regulating one's emotions, on the one hand, and the enacting of feeling rules, on the other.

A straightforward way to enter this issue is by considering the discussion of emotional labor and management in Hochschild's study on the commercialization of emotions in the service industry. Hochschild defines emotional labor as "the management of feeling to create a publicly observable facial and bodily display; emotional labor is sold for a wage and therefore has 'exchange value"' $(1983,7)$. Emotion management is performed "under the guidance of feeling rules", rules that are "standards used in emotional conversation [in the wide sense of social exchange; T.S.] to determine what is rightly owed and owing in the currency of feeling" (ibid., 18). The significant point is that the appropriate measure of owing and ownership is not determined by oneself but by others. This is especially true in the context of public or professional, typically unequal and often even exploitative exchange. Now, as we have already seen (sec. 1), Hochschild claims that it is precisely alienation that such emotional labor shares with its physical counterpart, and in particular the alienation from one's emotions that one literally 'puts to 
work' for the sake of others and one's own economic survival (ibid., 7). To be sure, within the veritable industry of studies on emotional labor undertaken since the appearance of Hochschild's classic (e.g., Bolton 2005; Guy et al. 2009; see for reviews Steinberg \& Figart 1999; Brewer 2011), there is no unanimous consensus as to the psychophysical and social harms of emotional labor. Some have even been skeptical as to whether the affective life of individuals exercising emotional labor wouldn't more robustly or altogether resist alienation (see for review Brook 2009). Yet, most agree that there is an intimate connection between emotion management and emotional alienation.

There are various mechanisms that explain this connection: for one, we again have a lack of personal investment in the emotion, which results in a feeling of not only non-appropriation, but lack of responsibility. This resonates with what I analyzed above in terms of a lack of personal commitment. What takes precedence over personal investment is not only the instrumentally employed signal function of emotions and their expression (cf. Hochschild 1983, 22); as we have seen, an important point for Hochschild is that, in enacting emotional rules and conventions, the "person's contribution of feeling (...) becomes less freighted with consequence" (ibid., 13). Whereas my sincere disdain and its illconcealed expression directed at my best friend potentially bears enormous personal significance, affecting my social life as a whole and drawing us "out from the sidelines", a barista's ill-concealed, but CCTV-recorded, disdainful looks and cynical remarks regarding the bad taste of a customer will likely only result in his being reprimanded by the shop-manager.

Notice also that emotional self-management is not simply a matter of artificial inducement or deliberate suppression of feelings, just as little as emotion management is a brute imposition of feeling rules upon emotional laborers ${ }^{11}$; emotion management is more subtle. Moreover, it involves one's own doing (otherwise, recall, we wouldn't have ESA). Specifically, it involves internalized and bodily-incorporated emotion-regulatory processes, standards, and often even external 'affective scaffolding' (Krueger \& Szanto 2017), such as make-up, uniforms, bodily drills, music, drugs, etc. In regulating emotions, we are "influencing which emotions one has, when one has them, and how one experiences and expresses these emotions" (Gross 1998, 271). For example we select and adjust the situations of affective import and modulate our attention or behavioural responses (Szanto 2017a). In alienating emotion management, ordinary regulatory processes, however, take prevalence over any other dimension of emotions, and in

\footnotetext{
${ }^{11}$ Even if Hochschild herself sometimes employs formulations that suggest the contrary; cf. e.g.: “"emotional labor' [requires] one to induce or suppress feelings in order to sustain the outward countenance that produces the proper state of mind in others" $(1983,7)$.
} 
particular their affective-intentional one. We might call this 'emotional overregulation'. ${ }^{12}$ Here, the subject doesn't lose all command or control over her emotional life; rather, there is an all too strong command, and it is experienced as heteronomous. Though one still experiences the emotion as a result of one's own performing the regulatory processes, these processes themselves are not appropriated, but rather socially or corporately enforced. The result is a feeling of uneasiness with one's own emotional labor. To put it in the language of economics: if my emotions owe too much to heterogeneous norms and socio-economic constraints, I may become unable to properly own up to them. And even if I am my own emotion manager, I feel as if I lose command over them. Again, my emotions are still mine, in the sense that it is I who regulates them, but what is thus managed is not owed to myself nor owned by me. In overregulating my emotions, I become their manager, but what I manage is not my own property. Paraphrasing Goldie's dictum, we might say that I'm not thinking with feeling but thinking that I should feel. ${ }^{13}$

\section{Concluding Remarks: What is Emotional Appropriation?}

I have argued that emotional self-alienation entails three interlinked dimensions: first, it involves a cleavage of the affective and the intentional dimensions of emotions understood as felt evaluations. There is not just a gap between the (blurred) affective-evaluative focus and the intentional value-properties of the target; moreover, there is a deficient affective relation, a lack of affective impact of the emotion on the person having it, and furthermore a deficiency in appropriately integrating the evaluation into her overall evaluative outlook. Secondly, ESA involves a deficiency in the self-disclosing function of emotions and accordingly results in disrupting personal self-elaboration. Finally, due to exceeding emotional labor and overregulation, ESA involves the lack of appropriating feeling rules or ownership and a resulting lack of personal commitment to and responsibility for one's emotions. So what is the thread that connects these three deficiencies? As should be apparent, it is the lack of personal affective impact or involvement in one's own emotions and their objects.

Now, even if one were to accept my argument, an inclination to protest its very premises and potential consequences might have been mounting all along. For surely, even for highly stable personalities, our personal commitments and

12 For an interesting recent discussion of heternonomy and autonomy in regulating moral emotions, see Harcourt 2016.

${ }^{13}$ For a related interesting analysis of ESA as the gap between what I should feel, according to what an emotion 'promises', and what I actually feel, see Ahmed 2010, 42. 
involvements change. But doesn't the assumption of some overall evaluative outlook militate against the rather natural idea that we develop ourselves, and value things, events and persons differently at different times in our life? Our world does not come furnished with a prefixed set of entities that matter to us, just as our 'selves' are not immobile within that world. In a similar vein, even those sympathetic to Hochschild's critical sociology of emotional commodification have challenged her austere distinction between 'true' and 'false' and the corresponding dichotomization of private and public selves (e.g., Wouters 1989). Even those who aren't impressed by the anti-essentialist lessons from various camps of the poststructuralist paradigm of the "contingency of selfhood" (Rorty 1989; cf. Jaeggi 2005, 209-215), or feminist critiques of authenticity, must take this type of challenge seriously. ${ }^{14}$

Moreover, according to the view I have defended, isn't the key to the ongoing process of redefining ourselves and recalibrating what matters to us precisely to experience new or re-appropriate previous emotions? Isn't a crucial part of personal self-elaboration and emotional education to adapt our emotional sensitivity and dispositions to ever-changing affective environments and demands? This is indeed so.

A closely related worry seems even more devastating. Doesn't the very conception of emotional self-alienation presuppose a conception of re-appropriation, which inevitably rests on a dubious conception of authenticity, or the idea of there being some 'private', 'true', 'natural' or 'self-transparent' emotions? But aren't emotions, even allegedly basic emotions, such as fear, disgust, anger, etc., always socio-culturally mediated, normed, co-determined or even coconstituted-as indeed a whole generation of philosophers, psychologists, and sociologists, including the ones referenced here, have forcefully argued? Whereas the defensible answer to the first question is negative, the answer to the latter is straightforwardly positive.

I cannot here dwell on a detailed refutation of the objection to a false conception of authentic emotions; nor can I dwell on elaborating the intrinsic sociality of emotions (cf. Szanto 2017a). Instead, let me gather those strands of my analysis that already point to why I think that the very conception of emotional alienation does not presuppose the idea of non-social, private or natural emotions or some essentialist conception of the self, and close with some brief remarks on what emotional self-appropriation is not.

First, appropriating one's emotions ought in no way lead to endorsing some kind of 'feel-yourself' esotericism, new romanticism, or emotional self-awareness

\footnotetext{
14 A good starting point for engaging with this, however diverse, line of criticism is to consult the contributions of Judith Butler, Raymond Geuss, and Jonathan Lear in Honneth 2008.
} 
of the sort propagated by self-help books one finds in airport bookstores with the author's name followed by a suggestive 'Ph.d.' or 'MD' (cf. Illouz 2008). Recall that the appropriateness of emotions is an affective-intentional and normative matter. The appropriateness of emotions as intentional feelings of import is essentially co-determined by intra-personal embeddedness (in one's overall evaluative outlook) and by their responsiveness to external evaluative warrants. Accordingly, as we have seen with Scheler, Helm and Pugmire, emotional integrity and depth have nothing to do with some internalist construal of more 'intensively' feeling or more carefully attending to one's own (bodily) sensations; rather they depend on the complex intentional relation of how my emotions cohere with one another and with the value-properties of the objects, events and persons revealed by them. Affective authenticity and emotional appropriation then means an everinconclusive sensitization to one's disposition to be affectively open to things that truly matter to us and that we care about. As a process of thus cultivating our emotions it also involves an ongoing critical reevaluation of our own emotions and the values revealed therein, and not least in light of other's evaluative stances.

This admittedly still very abstract picture is also meant to inhibit a number of further misconceptions of emotional re-appropriation, notably emotional narcissism, or appeals to realism or paternalism. Emphasizing and cultivating the self-revelatory character of emotions, or emotional self-elaboration, is not meant to advocate a solipsistic "inward" or "self-referential turn in emotion". Emotions ought not (only) matter to me, because it is I who feels or has them, as they reverberate in my affective echo chamber, and in particular not if this "subverts" my relation to others (Pugmire 2005, 106-109). Feeling insulted by your remark about my behaviour should not be narcissistically inflated, as it would be were I to feel insulted by the mere fact that the remark is directed to me, thus eclipsing the (affective) assessment of whether my behaviour in fact deserved your reprimand. Instead of such "emotional narcissism" (Pugmire 2005), the ineliminable selfinvolvedness of emotions should not lead us to ignore the essentially relational, i.e. self-, other-, and world-related, dimension of emotions, nor their subjectindependent warrantability.

Conversely, however, this should neither support the case for some version of value realism, according to which there are some invariable correspondences or non-contextual standards for the appropriate relation between felt evaluations and objective value-properties. Affective import is not only deeply shaped by socio-cultural, contextual factors, it is just as much determined by one's personal vantage point and the place the respective emotions occupy within one's overall evaluative pattern. If appropriate, emotions at the same time disclose objective value-properties and our own evaluative stances; moreover, they incorporate our 
relations to our closest and more distant 'fellow-feelers'. Consequently, a proper conception of emotional re-appropriation will not be vulnerable to anti-realist or anti-paternalistic, liberal critiques of alienation (cf. Jaeggi 2005), according to which the concept allegedly presupposes an invariable, objective or top-down determined set of socio-normative standards for having the right emotions, or feeling them properly.

Quite the contrary, emotional re-appropriation is a project that neither entails a pre-given set of socio-normative emotional standards or values nor dismisses them in a subjectivist or internalist turn. Even if self-disclosing, authentic emotions will never reveal some 'pure' self or core of one's personal identity that would be untainted by social norms and roles. The self, or personal identity, is coconstituted by social roles. Instead of an anyway impossible retreat from social and public roles, then, by appropriating one's emotions one ought to reveal those roles that one cares about or seeks to be expressive of oneself. To be sure, a circularity lurks here, but it is not a vicious circle, for the self-revelatory role of emotions and their function to disclose values adhering to objects, events and persons are, as we have seen, just two correlative sides of their affective-intentional relation. But since emotions, even if self-involving and self-revelatory, are not selftransparent (there is no direct epistemic route from an emotion to the self, as it were), we must always be careful and first ask, both ourselves and others, whether we have a case of self-deception. The mere possibility of emotional selfdeception, however, does not in principle preclude the possibility of emotional self-appropriation.

Revealing those social and public roles that one can identify with or wish to be expressive of oneself obviously cannot be a private enterprise; nor can it be achieved simply by emotional education. No ontological or existentialist project to re-establish emotional authenticity in a Heideggerian fashion, to combat our 'fallenness' into certain everyday practices or shared emotional norms (cf. Crowell 2015; Poellner 2015; Withy 2015; Wrathall 2015), will suffice either. Rather, what we need is social and institutional criticism of certain "affective arrangements" (Slaby et al. forthcoming) and socio-technological scaffolds (cf. Krueger \& Szanto 2017). This is a very diverse setting and accordingly a highly complex enterprise. It will include the 'affective re-design' of commercial or consumer environments, corporate and workplace architecture and interaction, virtual platforms (in particular dating sites, the design and use of emojis and memes), various forms of media, political and ritualistic interactions, educational practices, etc. (cf. Slaby 2017; Mühlhoff forthcoming). Only with appropriate institutional design and corporate and social practices will our unemployment agent or flight attendant be less prone 
to experience self-alienated emotions. Their individual striving will not do alone. As Jaeggi suggestively puts it:

If authenticity can no longer be sought in a fictitious place outside social expectations and roles, then overcoming alienation means not overcoming the sociality that roles represent but appropriating and transforming them. This also means that overcoming alienation requires the availability of social roles and institutions that make identification and appropriation possible. (Jaeggi 2005, 217)

This will not be an easy task, but rather just as infinitely complex as our social and institutional realities are. But it can only get off the ground if one is clear about what, if anything, is deficient in emotional self-alienation. The next steps will have to engage in what I suggest to call a critical philosophy of emotions, and such a philosophy can only be social criticism if it pays heed to the fact that our emotions, even the most intimately appropriated ones, are no private properties.

\section{Acknowledgments}

Earlier versions of this paper were presented at University of Verona, University of Copenhagen and the Free University Berlin. I am indebted to the comments and suggestions I have received on these occasions and particularly grateful to Maria Chiara Bruttomesso, Henning Nörenberg, Jan Slaby and Carina Staal. I also wish to acknowledge generous funding for my work on this article within the framework of my European Union (EU) Horizon-2020 Marie Skłodowska-Curie Individual Fellowship project SHARE (655067): Shared Emotions, Group Membership, and Empathy.

\section{References}

Ahmed, Sara. 2010. The Promise of Happiness. Durham: Duke University Press.

Bolton, Sharon C. 2005. Emotion Management in the Workplace. Basingstoke: Palgrave Macmillan.

Brewer, Talbot 2011. "On Alienated Emotions." In Morality and the Emotions, ed. Carla Bagnoli, 276-99. Oxford: Oxford University Press.

Brook, Paul. 2009. “The Alienated Heart: Hochschild's 'Emotional Labour' Thesis and the Anticapitalist Politics of Alienation." Capital \& Class 33(2): 7-31.

Crowell, Steven G. 2015. "Responsibility, Autonomy and Affectivity. A Heideggerian Approach." In Heidegger, Authenticity and the Self. Themes form Division Two of Being and Time, ed. Denis McManus, 215-242. London: Routledge. 
Goffman, Erving. 1956. The Presentation of Self in Everyday Life. Edinburgh Social Sciences Research Centre.

Goldie, Peter. 2000. The Emotions. A Philosophical Exploration. Oxford: Oxford University Press.

Gross, James J. 1998. "The Emerging Field of Emotion Regulation: An Integrative Review." Review of General Psychology 2(5): 271-99.

Guy, Mary E., Meredith A. Newman, and Sharon H. Mastracci (eds). 2014. Emotional Labor: Putting the Service in Public Service. London: Routledge.

Harcourt, Edward. 2016. "Moral Emotion, Autonomy and the 'Extended Mind". Phenomenology and Mind (11): 100-12.

Heidegger, Martin. 1929-30. [1983]. The Fundamental Concepts of Metaphysics. World, Finitude, Solitude. Transl. by William McNeill, and Nicholas Walker. Bloomington: Indiana University Press.

Heller, Agnes. 1978. [2009]. A Theory of Feelings. Lanham, MD: Lexington.

Helm, Bennett W. 2001. Emotional Reason, Deliberation, Motivation, and the Nature of Value. Cambridge: Cambridge University Press.

Helm, Bennett W. 2009. Love, Friendship, and the Self: Intimacy, Identification, and the Social Nature of Persons. Oxford: Oxford University Press.

Hochschild, Arlie. 1979. "Emotion Work, Feeling Rules, and Social Structure." American Journal of Sociology, 85(3): 551-75.

Hochschild, Arlie R. 1983. The Managed Heart. Commercialization of Human Feeling. Berkley: University of California Press.

Honneth, Axel. 2008. Reification: A New Look at an Old Idea. With Commentaries by Judith Butler, Raymond Geuss, and Jonathan Lear. Ed. Martin Jay. Oxford: Oxford University Press.

Illouz, Eva. 2007. Cold Intimacies. The Making of Emotional Capitalism. Cambridge: Polity.

Illouz, Eva. 2008. Saving the Modern Soul: Therapy, Emotions, and the Culture of Self-Help. Berkley: University of California Press.

Jaeggi, Rahel. 2005. [2014]. Alienation. Transl. by Frederick Neuhouser, and Alan E. Smith. Ed. by Frederick Neuhouser. New York: Columbia University Press.

Krueger, Joel. 2014. "Varieties of Extended Emotions." Phenomenology and the Cognitive Sciences, 13(4): 533-55.

Krueger, Joel, and Thomas Szanto. 2016. "Extended Emotions." Philosophy Compass 11(12): 863-78.

León, Felipe, Szanto, Thomas, and Zahavi, Dan. Forthcoming. "Emotional Sharing and the Extended Mind." Synthese. doi: 10.1007/s11229-017-1351-x.

Nussbaum, Martha. 2001. Upheavals of Thought: The Intelligence of Emotions. Cambridge: Cambridge University Press.

Marx, Karl. 1844 [1975]. Economic and Philosophical Manuscripts (1844), In Karl Marx: Early Writings. London: Penguin/New Left Review.

McManus, Denis (ed.). 2015. Heidegger, Authenticity and the Self. Themes form Division Two of Being and Time. London: Routledge.

Mele, Alfred. 2001. Self-Deception Unmasked. Princeton: Princeton University Press. 
Moran, Richard. 2001. Authority and Estrangement: An Essay on Self-knowledge. Princeton: Princeton University Press.

Mühlhoff, Rainer. Forthcoming. Immersive Macht. Das Subjekt im Affektgeschehen. Sozialtheorie nach Foucault und Spinoza. Frankfurt am Main: Campus.

Sartre, Jean-Paul. 1943 [2003]. Being and Notbingness: An Essay on Phenomenological Ontology Trans. by Hazel E. Barnes. London: Routledge.]

Scheler, Max. 1919 [1955]. "Idole der Selbsterkenntnis." In Max Scheler: Vom Umsturz. der Werte. Abhandlungen und Aufsätze. Gesammelte Werke, Bd. 3, ed. Maria Scheler, 213-912. Bern: Francke [Engl.: "Idols of Self-Knowledge." In Max Scheler: Selected Philosophical Essays, 3-97. Evanston, Ill.: Northwestern University Press 1973.]

Schmid, Hans Bernhard. Forthcoming. "Authentic Role Play A Political Solution to an Existential Paradox."

Slaby, Jan. 2010. "The other side of existence: Heidegger on boredom", in Habitus in Habitat II: Other Sides of Cognition, ed. Sabine Flach, Daniel Margulies, and Jan Söffner, 101-120, Bern: Peter Lang.

Slaby, Jan. 2014. 'Emotions and the Extended mind.' Collective emotions. Perspectives from Psychology, and Sociology, ed. Christian von Scheve, and Mikko Salmela, 32-46. Oxford: Oxford University Press.

Slaby, Jan. 2017. "Mind Invasion: Situated Affectivity and the Corporate Life Hack." Frontiers of Psychology 7. doi: 10.3389/fpsyg.2016.00266.

Slaby, Jan, and Achim Stephan. 2008. "Affective Intentionality and Self-Consciousness." Consciousness and Cognition 17(2): 506-13.

Slaby, Jan, Paskaleva, Asena, and Achim Stephan. 2013. Enactive Emotion and Impaired Agency in Depression. Journal of Consciousness Studies 20(7-8): 33-55.

Slaby, Jan, Rainer Mühlhoff, and Philipp Wüschner. Forthcoming. "Affective Arrangements." Emotion Review.

Steinberg, Ronnie J., and Deborah M. Figart. 1999. "Emotional labor since The Managed Heart." The Annals of the American Academy of Political and Social Science 561(1): 8-26.

Szanto, Thomas. 2015. "Collective Emotions, Normativity and Empathy: A Steinian Account." Human Studies 38(4), 503-27.

Szanto, Thomas. 2017a. "Collaborative Irrationality, Akrasia and Groupthink: Social Disruptions of Emotion Regulation." Frontiers in Psychology 7(2002): 1-17.

Szanto, Thomas. 2017b. Forthcoming. "The Phenomenology of Shared Emotions: Reassessing Gerda Walther." In Woman Phenomenologists on Social Ontology, ed. Sebastian Luft, and Ruth Hagengruber. Dordrecht: Springer.

Tracy, Sarah J. 2009. "Becoming a character for commerce: Emotion labor, selfsubordination, and discursive construction of identity in a total institution." Management communication quarterly 14(1): 90-128.

Poellner, Peter. 2015. In Heidegger, Authenticity and the Self. Themes form Division Themes from Division Two of Being and Time, ed. Denis McManus, 243-62. London: Routledge.

Pugmire, David. 2005. Sound Sentiments. Integrity in the Emotions. Oxford: Oxford University Press. 
Ratcliffe, Matthew. 2015. Experiences of Depression: A Study in Phenomenology. Oxford: Oxford University Press.

Rorty, Richard. 1989. Contingency, Irony, Solidarity. Cambridge: Cambridge University Press.

Wouters, Cas. 1989. "The Sociology of Emotions and Flight Attendants: Hochschild's Managed Heart." Theory, Culture \& Society 6(1): 95-123.

Wrathall, Mark A. 2015. "Autonomy, Authenticity and the Self." In Heidegger, Authenticity and the Self. Themes form Division Two of Being and Time, ed. Denis McManus, 193214. London: Routledge.

Withy, Katherine. 2015. "Owned Emotions: Affective excellence in Heidegger on Aristotle." In Heidegger, Authenticity and the Self. Themes form Division Two of Being and Time, ed. Denis McManus, 21-36. London: Routledge. 